\section{material kedokteran gigi}

ISSN 2302-5271

\title{
Evaluasi nilai kekerasan resin komposit bulkfill dengan variasi waktu penyinaran sinar LED
}

\section{Atia Nurul Sidiqa}

Departemen Ilmu dan Teknologi Material Kedokteran Gigi

Program Studi Kedokteran Gigi Universitas Jenderal Achmad Yani

\section{Badi Soerachman}

Departemen Endodontologi dan Konservasi Gigi

Program Studi Kedokteran Gigi Universitas Jenderal Achmad Yani

\section{Mutiara Yulina Putri}

Program Studi Kedokteran Gigi Universitas Jenderal Achmad Yani

\section{Abstrak}

Resin komposit bulkfill dapat ditempatkan pada kavitas secara langsung dengan ketebalan polimerisasi sampai $4 \mathrm{~mm}$ dan disinari selama 10 detik dengan LED. Waktu penyinaran merupakan salah satu faktor yang mempengaruhi kekerasan bahan resin komposit. Tujuan untuk mengetahui perbedaan waktu penyinaran dengan LED terhadap nilai kekerasan resin komposit bulkfill. Penelitian ini bersifat eksperimental murni. Sampel resin komposit bulkfill dengan diameter $6 \mathrm{~mm}$ dan ketebalan $4 \mathrm{~mm}$, sebanyak 15 buah yang dibagi menjadi 3 kelompok dan disinari LED dengan intensitas $1000 \mathrm{~mW} / \mathrm{cm} 2$. Kelompok 1 disinari selama 10 detik, kelompok 2 disinari selama 20 detik dan kelompok 3 disinari selama 40 detik. Sampel direndam dalam air destilasi dengan suhu $37^{\circ} \mathrm{C}$ selama 24 jam lalu dilakukan pengukuran uji kekerasan menggunakan de9 ngan Vickers Microhardness Tester beban 100 gram dengan waktu 15 detik. Perhitungan rasio kekerasan yaitu kekerasan permukaan bawah dibagi kekerasan permukaan atas. Uji analisis statistik yang digunakan pada penelitian ini yaitu uji Shapiro-Wilk dan One Way Anova tidak berpasangan dilanjut uji Post Hoc menggunakan uji Bonferroni. Rasio kekerasan komposit perbandingan kelompok 10 detik dan 20 detik dan kelompok 20 detik dan 40 detik adalah tidak beda signifikan, sedangkan untuk perbandingan kelompok 10 detik dan 40 detik memiliki perbedaan yang bermakna. Berdasarkan penelitian ini waktu penyinaran resin komposit mempengaruhi tingkat kekerasan resin komposit. Hal ini membuktikan bahwa semakin banyak monomer yang terpolimerisasi menghasilkan material resin komposit yang lebih padat dengan kekerasan

Tautan versi e-jurnal: http://jurnal.pdgi.or.id/index.php/jmkg/article/view/367 
Atia Nurul S: Evaluasi nilai kekerasan resin komposit bulkfill dengan variasi waktu penyinaran sinar LED

yang meningkat. Simpulan, waktu penyinaran akan meningkatkan nilai kekerasan resin komposit.

Kata kunci: kekerasan, light-emitting diode (LED), resin komposit bulkfill, waktu penyinaran.

\begin{abstract}
Bulkfill composite resin can be applied in "bulk" up to $4 \mathrm{~mm}$ and it can be cures with LED curing lights in 10 seconds. Time exposure affects the hardness of the composite resin material. This experiment aims to determine differences in exposure time with LED on the hardness of bulkfill composite resin. This experiment is a true experiment. The samples are bulkfill composite resin with diameter of $6 \mathrm{~mm}$ and thickness of $4 \mathrm{~mm}$. There were 3 groups of samples $(n=5)$ and cured with LED with intensity $1000 \mathrm{~mW} / \mathrm{cm}^{2}$. Group 1 was exposed for 10 seconds, group 2 for 20 seconds, and group 3 for 40 seconds. The samples were soaked in distilled water $37^{\circ} \mathrm{C}$ for 24 hours in waterbath. Microvickers hardness with the load of 100 grams in 15 seconds applied to the samples on the lower and the upper surface. The result found that the ratio of hardness both 10 seconds and 20 seconds, and 20 seconds and 40 seconds are no significant. The ratio hardness of 10 seconds and 40 seconds had significant difference. Based on the research irradiation time effect resin bulkfill composite hardness. It means that the more monomer polymerized the more higher hardness could be achived. The longer exposure time can make increases hardness level.
\end{abstract}

Keywords: Bulkfill composite resin, exposure time, hardness, light-emitting diode (LED).

\section{Pendahuluan}

Penempatan restorasi komposit konvensional pada bagian posterior menggunakan teknik incremental dengan ketebalan 2 $\mathrm{mm}$ membutuhkan waktu yang lama, meningkatnya risiko terjebaknya gelembung udara dan kontaminasi disetiap lapisannya. ${ }^{1}$ Jika penempatan dan penyinaran resin komposit tidak sempurna maka polimerisasinya juga tidak akan sempurna. Hal ini menyebabkan terbentuknya celah sehingga tambalan mudah pecah dan terlepas. ${ }^{2,3}$ Penelitian secara in-vitro menyatakan bahwa terjadi pengerasan resin komposit dengan ketebalan 3,5 mm sampai $5,5 \mathrm{~mm}$ dalam satu kali aplikasi. Resin komposit bulkfill ditambahkan suatu bahan inisiasi polimerisasi sehingga hanya dibutuhkan waktu penyinaran selama 10 detik untuk mencapai polimerisasi yang optimal. ${ }^{1,2}$

Aktivasi polimerisasi resin komposit terjadi karena reaksi kimia dan cahaya tampak. Proses polimerisasi resin komposit dengan aktivasi cahaya tampak dilakukan dengan Light-Emitting Diode (LED), QuatrzTungsten-Halogen (QTH), Plasma Arc Curing (PAC) lamp, dan Argon Laser Lamp. Penggunaan Light- Emitting Diode (LED) memberikan keunggulan dibanding sumber sinar lainnya yaitu membutuhkan daya listrik 
rendah, dapat menggunakan baterai, tidak mengeluarkan panas, tidak berisik, karena tidak membutuhkan kipas pendingin dan tidak membutuhkan filter cahaya. ${ }^{4}$

Keberhasilan polimerisasi resin komposit dipengaruhi oleh beberapa faktor eksternal yaitu jenis alat penyinaran, intensitas sinar, jarak ujung tip LED yang sedekat mungkin dengan permukaan resin komposit, sudut penyinaran dan waktu penyinaran. Waktu penyinaran yang kurang akan mengakibatkan polimerisasi terjadi pada lapisan luar saja dan menghasilkan lapisan lunak pada bagian dasar. Polimerisasi yang sempurna dipengaruhi oleh ketebalan bahan dan waktu penyinaran. Keberhasilan polimerisasi dapat ditentukan dari rasio kekerasan permukaan resin komposit.

Tingkat kekerasan digunakan untuk mengevaluasi ketahanan terhadap pemakaian dan menentukan derajat perubahan bentuk suatu bahan terhadap indentasi suatu beban. Kekerasan resin komposit adalah ketahanan suatu bahan resin komposit menahan indentasi atau penetrasi dengan suatu beban. ${ }^{5}$ Alat yang sering digunakan untuk menguji kekerasan salah satunya Vickers Microhardness Tester. Pengukuran kekerasan tersebut dengan membandingkan kekerasan permukaan bawah dan atas sehingga didapatkan rasio kekerasan resin komposit.

\section{Metode penelitian}

Sampel resin komposit bulkfill diameter 6 $\mathrm{mm}$ dan ketebalan $4 \mathrm{~mm}$, sebanyak 15 buah dibagi menjadi 3 kelompok dan disinari LED dengan intensitas $1000 \mathrm{~mW} / \mathrm{cm} 2$. Kelompok 1 disinari selama 10 detik, kelompok 2 disinari selama 20 detik dan kelompok 3 disinari selama 40 detik. Seluruh sampel kemudian direndam dalam air destilasi dengan suhu 370 C selama 24 jam lalu dilakukan pengukuran uji kekerasan menggunakan Vickers Microhardness Tester beban 100 gram dengan waktu 15 detik. Perhitungan rasio kekerasan yaitu kekerasan permukaan bawah dibagi kekerasan permukaan atas. Uji analisis statistik yang digunakan pada penelitian ini yaitu uji Shapiro-Wilk dan One Way Anova tidak berpasangan dilanjut uji Post Hoc menggunakan uji Bonferroni.

\section{Hasil penelitian}

Hasil pengukuran kekerasan resin komposit bulkfill pada kelompok 1 menunjukan besar nilai kekerasan terendah sebesar 36,8 VHN pada sampel ke-4 pada permukaan bawah dan besar nilai kekerasan tertinggi sebesar $56,7 \mathrm{VHN}$ pada sampel ke-2 pada permukaan atas. Rasio kekerasan terendah sebesar 0,685 pada sampel ke-4. Rasio kekerasan tertinggi sebesar 0,792 pada sampel ke-2. Rata-rata kekerasan pada permukaan setiap sampel sebesar 46,68 VHN dengan rasio 0,732.

Berdasarkan tabel 1 tingkat kekerasan permukaan atas lebih tinggi dibandingkan permukaan bawah. Berdasarkan ISO 4049 rasio kekerasan permukaan bawah dibagi dengan permukaan atas dengan ketebalan $4 \mathrm{~mm}$ setelah dilakukan perendaman selama 24 jam diatas 0,8.1 Pada Tabel 1 rasio kekerasan resin komposit bulkfill yang disinari dengan LED selama 10 detik memiliki rasio kekerasan dibawah 0,8. Hal ini membuktikan bahwa waktu penyinaran 10 detik belum cukup memenuhi rasio kekerasan.

Hasil pengukuran kekerasan resin komposit bulkfill pada kelompok 2 menunjukan besar nilai kekerasan terendah sebesar 50,5 VHN pada sampel ke-5 pada permukaan bawah dan besar nilai kekerasan tertinggi sebesar 62,5 VHN pada sampel ke-4 pada permukaan atas. Rasio kekerasan terendah sebesar 0,746 pada sampel ke2. Rasio kekerasan tertinggi sebesar 0,884

Tabel 1. Nilai kekerasan resin komposit bulkfill pada kelompok 1

\begin{tabular}{cccc}
\hline Sampel & $\begin{array}{c}\text { Atas } \\
(\text { VHN })\end{array}$ & $\begin{array}{c}\text { Bawah } \\
(\text { VHN })\end{array}$ & $\begin{array}{c}\text { Rasio } \\
\text { Kekerasan }\end{array}$ \\
\hline 1 & 52,4 & 39,1 & 0,75 \\
2 & 56,7 & 44,9 & 0,79 \\
3 & 51,0 & 38,1 & 0,75 \\
4 & 53,7 & 36,8 & 0,68 \\
5 & 55,6 & 38,5 & 0,69 \\
\hline Rata-rata & 53,88 & 39.48 & 0,73 \\
\hline
\end{tabular}


Atia Nurul S: Evaluasi nilai kekerasan resin komposit bulkfill dengan variasi waktu penyinaran sinar LED

Tabel 2 Nilai kekerasan resin komposit bulkfill pada kelompok 2

\begin{tabular}{cccc}
\hline Sampel & $\begin{array}{c}\text { Atas } \\
(\text { VHN })\end{array}$ & $\begin{array}{c}\text { Bawah } \\
(\text { VHN })\end{array}$ & $\begin{array}{c}\text { Rasio } \\
\text { Kekerasan }\end{array}$ \\
\hline 1 & 61,50 & 54,00 & 0,88 \\
2 & 62,20 & 46,40 & 0,75 \\
3 & 64,00 & 52,00 & 0,813 \\
4 & 62,50 & 50,60 & 0,810 \\
5 & 57,10 & 50,50 & 0,884 \\
\hline Rata-rata & 61,46 & 50,70 & 0,826 \\
\hline
\end{tabular}

Tabel 3 Nilai kekerasan resin komposit bulkfill pada kelompok 3.

\begin{tabular}{cccc}
\hline Sampel & $\begin{array}{c}\text { Atas } \\
(\mathrm{VHN})\end{array}$ & $\begin{array}{c}\text { Bawah } \\
(\mathrm{VHN})\end{array}$ & $\begin{array}{c}\text { Rasio } \\
\text { Kekerasan }\end{array}$ \\
\hline 1 & 60,7 & 55,7 & 0,918 \\
2 & 61,9 & 58,8 & 0,950 \\
3 & 54,9 & 45,1 & 0,821 \\
4 & 64,7 & 60,8 & 0,940 \\
5 & 67,5 & 48,8 & 0,723 \\
\hline Rata-rata & 61,94 & 53,84 & 0,870 \\
\hline
\end{tabular}

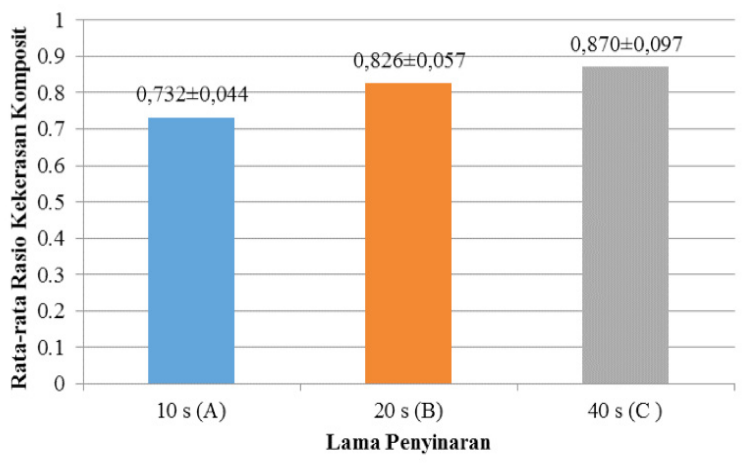

Gambar 1. Hubungan antara lama penyinaran dan nilai kekerasan

pada sampel ke-5. Rata-rata kekerasan pada permukaan setiap sampel sebesar 56,08 VHN dengan rasio 0,826 .

Pada Tabel 2 rasio kekerasan resin komposit bulkfill yang disinari dengan LED selama 20 detik memiliki rasio kekerasan diatas 0,8 . Hal ini membuktikan bahwa waktu penyinaran 20 detik telah cukup memenuhi rasio kekerasan. Hasil pengukuran kekerasan resin komposit bulkfill pada kelompok 3 menunjukan besar nilai kekerasan terendah sebesar 45,1 VHN pada sampel ke-3 pada permukaan bawah dan besar nilai kekerasan tertinggi sebesar 67,5 VHN pada sampel ke-5 pada permukaan atas. Rasio kekerasan terendah sebesar 0,723 pada sampel ke-5. Rasio kekerasan tertinggi sebesar 0,95 pada sampel ke-2 . Rata-rata kekerasan pada permukaan setiap sampel sebesar 57,89 VHN dengan rasio 0,87 .

Pada gambar 1 terlihat bahwa nilai rata-rata kekerasan komposit bulk fill dengan menggunakan berbagai macam waktu penyinaran light-emitting diode (LED) yaitu cenderung relatif bervariasi tingkat kekerasan resin komposit bulkfill setiap kelompok perlakuan dilihat dari nilai ratarata dan simpangan bakunya. Hasil pengujian anova menunjukan bahwa ketiga perlakuan (waktu penyinaran) tersebut adalah berbeda signifikan dengan nilai sigifikansi cenderung di bawah 0,05. Berdasarkan hasil pengujian uji lanjut setelah anova menggunakan uji bonferroni dapat disimpulkan bahwa untuk pengukuran terhadap parameter kekerasan komposit perbandingan pasangan kelompok 10 detik dan 20 detik dan pasangan kelompok 20 detik dan 40 detik adalah tidak beda signifikan $(p>0,05)$, sedangkan untuk pasangan perbandingan kelompok 10 detik dan 40 detik memiliki perbedaan yang bermakna $(p<0,05)$.

\section{Pembahasan}

Dalam penelitian ini resin komposit bulkfill dengan ketebalan $4 \mathrm{~mm}$ yang disinari LED dengan intensitas $1000 \mathrm{~mW} / \mathrm{cm}^{2}$ selama 10, 20,dan 40 detik. Berdasarkan hasil penelitian yang sudah didapat terlihat bahwa penyinaran 10 dan 40 detik yang memiliki perbedaan.

Resin kompositbulkfilldengan ketebalan $4 \mathrm{~mm}$ dapat dilakukan penyinaran selama 10 detik dikarenakan memiliki photoinitiators ivocerin. Pada penelitian Singhal $\mathrm{S}$ et al pada tahun 2013, dikemukakan bahwa rasio kekerasan resin komposit bulkfill telah melebihi rasio keberhasilan polimerisasi. Pada penelitian ini rasio kekerasannya masih dibawah 0,8 . dan waktu penyinaran 10 detik belum cukup untuk memenuhi keberhasilan polimerisasi resin komposit. Hal ini terjadi karena polimerisasi bahan resin komposit tidak berlangsung dengan baik akibat adanya 
perbedaan variabel tempat, alat dan bahan yang digunakan berbeda dengan penelitian sebelumnya dan terdapat beberapa variabel perancu. Rasio kekerasan resin komposit bulkfill dengan ketebalan $4 \mathrm{~mm}$ dilakukan penyinaran selama 20 dan 40 detik telah memenuhi rasio keberhasilan polimerisasi resin komposit. Berdasarkan penelitian ini waktu penyinaran resin komposit mempengaruhi tingkat kekerasan resin komposit. Semakin lama waktu penyinaran resin komposit maka tingkat kekerasan resin komposit meningkat. Hal ini membuktikan bahwa semakin banyak monomer yang terpolimerisasi sehingga didapatkan material resin komposit yang lebih padat dengan

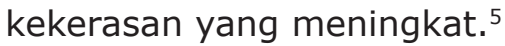

Kekerasan resin komposit bulkfill jika dibandingkan penyinaran 10 detik dan 40 detik memiliki perbedaan yang bermakna sedangkan 10 dan 20 detik dan pasangan 20 dan 40 detik tidak beda signifikan. Hal ini dikarenakan jarak antara 10 detik dan 40 detik cukup lama. Berdasarkan data penelitian kekerasan maksimum didapatkan pada resin komposit yang disinari selama 40 detik. Lama waktu penyinaran resin komposit bulkfill dengan ketebalan $4 \mathrm{~mm}$ sebaiknya dilakukan minimal 20 detik untuk memperoleh rasio kekerasan yang sesuai dengan keberhasilan polimerisasi resin komposit.

\section{Simpulan}

Berdasarkan hasil penelitian waktu penyinaran resin komposit bulkfill terhadap kekerasan dengan menggunakan sumber sinar LED dapat disimpulkan bahwa penyinaran mempengaruhi kekerasan resin komposit bulkfill.

\section{Penghargaan}

Penelitian ini merupakan bagian dari Hibah Internal LPPM Unjani

\section{Daftar pustaka}

1. Al-Mansour $\mathrm{K}, \mathrm{Al}$-Sada $\mathrm{A}, \mathrm{Al}$-Sinan $\mathrm{H}$. Curing depth of bulkfill composites an invitro study. Pakistan oral \& dental journal 2015;35:270-74.

2. Orlowski M, Tarczydlo B, Chalas R. Evaluation of marginal integrity of four bulkfill dental composite material in-vitro study. Hindawl Publishing Corporation The Scientific World Journal; 2015:1-8.

2. Vasquez D. A new-generation bulkfill composite for direct posterior restorations, Inside Dentistry May 2012; 8(5).

3. Garg N, Garg A. Composite restorations. In: Garg N, editor. Textbook of operative dentistry. 2nd ed. New Delhi Panama City London Dhaka Kathmandu: Jaype Brothers Medical Publishers ( $P$ ) Ltd; 2013. p. 299-351.

4. Lombardini M, Chiesa M, Schribante A, et al. Influence of polymerization time and depth of cure of resin composites determined by Vickers hardness. Dental Research Journal Nov-Dec 2012; 9(6): 735-40. 